\title{
An Ecofriendly Synthesis of 2-oxazolidinone From 2- aminoethanol and Urea Under Solvent-free Condition Using CeO2 Nanoparticles
}

\author{
ALI NEMATI KHARAT ( $\nabla$ anemati@ut.ac.ir) \\ University of Tehran https://orcid.org/0000-0003-2225-2789 \\ Mehrnaz Aliahmadi \\ School of Chemistry, College of Science, University of Tehran, Tehran, Iran
}

\section{Research Article}

Keywords: 2-aminoethanol, $\mathrm{CeO} 2, \mathrm{CO} 2$ fixation, Heterogeneous catalyst, 2-oxazolidinone, Urea

Posted Date: May 20th, 2021

DOl: https://doi.org/10.21203/rs.3.rs-535619/v1

License: (c) (1) This work is licensed under a Creative Commons Attribution 4.0 International License.

Read Full License 


\title{
An ecofriendly synthesis of 2-oxazolidinone from 2-aminoethanol and urea under solvent-free condition using $\mathrm{CeO}_{2}$ nanoparticles
}

\author{
Mehrnaz Aliahmadi, Ali Nemati Kharat* \\ School of Chemistry, College of Science, University of Tehran, Tehran, Iran \\ Tel: +98-21-61112499, E-mail: alnema@khayam.ut.ac.ir
}

\begin{abstract}
Cerium dioxide nanoparticles were prepared by the sol-gel method using cellulose as a template and used in the synthesis of 2-oxazolidinone from urea and 2-aminoethanol under solvent-free conditions. All the reaction parameters were optimized to obtain the best selectivity and conversion. The selectivity of $100 \%$ to 2-oxazolidinone with a pretty complete conversion of about $98.4 \%$ was achieved. The prepared catalyst was characterized by Scanning Electron Microscopy (SEM), X-ray Diffraction (XRD), and volumetric isothermal nitrogen gas adsorptiondesorption method (BET).
\end{abstract}

Keywords: 2-aminoethanol, $\mathrm{CeO}_{2}, \mathrm{CO}_{2}$ fixation, Heterogeneous catalyst, 2-oxazolidinone, Urea. 


\section{Introduction}

Global warming and climate changes, caused by emitted greenhouse gases, have seriously affected human life and the ecological environment [1,2]. According to a recently published report by the Intergovernmental Panel on Climate Change about global warming, the total global temperature has risen 1.5 degrees above the pre-industrial amount due to the increase in greenhouse gases emission $[3,4]$. Among greenhouse gases, carbon dioxide is the main major gas that contributes to the Earth's climate changes. Hence, there is an urgent need to decrease the emission of this greenhouse gas into the atmosphere. Therefore, several strategies have been developed for the separation, storage, and utilization of $\mathrm{CO}_{2}$ to mitigate the concentration of $\mathrm{CO}_{2}$ in the atmosphere. [5-7]. Using carbon dioxide as an economical, safe, and renewable carbon resource is attractive from the viewpoint of synthetic chemistry. The utilization of $\mathrm{CO}_{2}$ as a $\mathrm{C}_{1}$ building block for synthesizing high-value organic chemicals has gained much more attention. Converting $\mathrm{CO}_{2}$ to industrial chemical products is a route for recycling carbon and carbon-containing materials [8,9]. Cyclic carbamates are one of the most important target compounds of conversion of $\mathrm{CO}_{2}$, having several applications in both the chemical industry and organic chemistry [10-13]. Conventionally, these nitrogen-containing heterocyclic compounds are synthesized using highly toxic reagents such as phosgene [14,15]. 2-oxazolidinones are important cyclic carbamates which are widely used in drugs [16], antibiotics [17], herbicides [18], organic synthesis [19], solvents for lithium-ion batteries and ink-jet printing [16]. Moreover, polymers containing 2-oxazolidinone are used for applications as foams, adhesives, and fibers [20]. There are several reported methods for synthesizing 2-oxazolidinone and its derivatives, such as carbonylation of $\beta$-amino alcohols with phosgene [21] or carbon monoxide [22], the addition of isocyanates to epoxides [23,24], and the reaction of isocyanates with propargylamines [25]. Owing to the toxicity and cost of mentioned reagents, 2-oxazolidinone can be greenly synthesized from $\mathrm{CO}_{2}$ and $\beta$-amino alcohols [26] or urea and vicinal diols [27,28]. Nontoxic urea with a lower price is a resource for carbon dioxide and can be used as an amination and carboxylation reagent, and reaction can be conducted at milder pressure of carbon dioxide [29]. Urea can further be reproduced by ammonia and $\mathrm{CO}_{2}$, so using urea instead of carbon dioxide could be considered as an indirect utilization of $\mathrm{CO}_{2}$ to form 2oxazolidinone [27,28,30]. Various catalytic systems are designed to improve reaction conditions and better efficiency to oxazolidinones. Kodaka, Dinsmore, and Mun oz have reported homogeneous catalytic systems composed of phosphines such as trialkylphosphine in the presence 
of a strong base for the synthesis of oxazolidinone compounds. This method suffered the separation of alkylphosphine oxide produced from products $[31,32]$. Other homogeneous catalysts such as organotin [33] or organoantimony complexes [34] and ionic liquid with alkali promoter [35] were developed to overcome previous drawbacks but resulted in moderate yields in severe reaction conditions of high temperature and pressure with long reaction times. Aluminum [36], vanadium [37], palladium [38], Ruthenium [27], chromium [23], and rare earth metals [39] complexes also catalyzed synthesis of 2-oxazolidinone but resulted in moderate yields. However, from environmental viewpoints and separation difficulties of homogenous catalysts, non-catalytic systems and heterogeneous systems are much more preferable. Arai et al. and Tominga et al. reported the non-catalytic synthesis of cyclic carbamates from $\mathrm{CO}_{2}$ and amino alcohols at $423 \mathrm{~K}$ and $453 \mathrm{~K}$, respectively, having problems such as low yields and narrow scope of amino alcohols [40]. As a heterogeneous catalyst, the reaction of $\mathrm{CO}_{2}$ with amino alcohols at $423 \mathrm{~K}$ and $2 \mathrm{MPa}$ were carried out over various metal oxides, and the formation rate of 2-oxazolidinone was compared [41]. In comparison with other metal oxides, $\mathrm{CeO}_{2}$ showed better results. $\mathrm{CeO}_{2}$ is an effective heterogeneous catalyst for several organic reactions. The acid-base property of $\mathrm{CeO}_{2}$ has a critical role in the activation of $\mathrm{CO}_{2}$ and amino alcohols.

In the present work, we report a solvent-free synthesis of 2-oxazolidinone from urea and 2aminoethanol using synthetic $\mathrm{CeO}_{2}$ nanoparticles as a heterogeneous catalyst.

\section{Experimental}

\subsection{Materials and instruments}

Cerium nitrate hydrate, 2-aminoethanol, urea, and cellulose were purchased from Merck Chemical Company and were used without further purification. X-ray diffraction (XRD) patterns were obtained by a Philips-X'pertpro X-ray diffractometer using Ni-filtered $\mathrm{Cu}$ Ka radiation. Scanning electron microscopy (SEM) was conducted using a Zeiss DSM 960A microscope with an acceleration voltage of $10 \mathrm{k}$. To determine the specific surface area and pore volume of the supported catalysts, a BELSORP mini instrument nitrogen adsorption-desorption equipment was used at $77 \mathrm{~K}$. For monitoring of reaction products and their identity, a gas chromatograph, Agilent Technologies 7890A Instrument, equipped with an HP-1 capillary column, an FID detector, and a mass spectroscope model $5975 \mathrm{C}$ with a triple-axis detector was used. 


\subsection{Synthesis of $\mathrm{CeO}_{2}$ nanoparticles}

Mesoporous $\mathrm{CeO}_{2}$ was prepared using the sol-gel method. First, a suspension was prepared by dispersing $20 \mathrm{~g}$ cellulose in water $(20 \% \mathrm{w} / \mathrm{w})$ and mixed for 30 minutes in an ultrasonic bath. A solution of $2 \mathrm{~g} \mathrm{Ce}\left(\mathrm{NO}_{3}\right) \cdot 6 \mathrm{H}_{2} \mathrm{O}$ in $40 \mathrm{ml}$ water was added dropwise into the suspension and stirred vigorously at $40^{\circ} \mathrm{C}$. After $15 \mathrm{~min}$, the ammonia solution was added to adjust the $\mathrm{pH}$ at 10 , and the sedimentation reaction was performed under reflux for 2 hours. Subsequently, the mixture was heated to $90{ }^{\circ} \mathrm{C}$ and aged for $24 \mathrm{~h}$. The resulting mixture was dried at $80^{\circ} \mathrm{C}$ overnight. The dried powder was then calcined at $500{ }^{\circ} \mathrm{C}$ for $5 \mathrm{~h}$. Finally, pale yellow ceria was stored in a closed container for the catalytic reaction.

\subsection{Catalytic synthesis of 2-oxazolidinone}

The procedure of the 2-oxazolidinone synthesis from 2-aminoethanol and urea was as follows: typically, $0.25 \mathrm{ml}$ of 2-aminoethanol and $0.25 \mathrm{~g}$ of urea and $0.025 \mathrm{~g}$ of ceria catalyst (10 w \%) were added into a stainless steel autoclave. The reaction was carried out at $150{ }^{\circ} \mathrm{C}$ for $4 \mathrm{~h}$ under constant stirring. Then the reaction mixture was cooled down to room temperature, and obtained product was dissolved in methanol. The catalyst was separated by centrifugation. The product was analyzed by gas chromatography using n-pentane as an internal standard.

\section{Result and discussion}

In order to investigate the crystalline structure and the average crystallite size of the prepared ceria powder, x-ray diffraction was used. The XRD pattern of synthesized cerium dioxide nanoparticles is shown in Figure 1. All diffracted peaks at $2 \theta$ values of $28.5^{\circ}, 33.1^{\circ}, 47.5^{\circ}, 56.4^{\circ}, 59.1^{\circ}, 69.5^{\circ}$, $76.7^{\circ}, 79.2^{\circ}$, and $88.4^{\circ}$, respectively correspond to the (111), (200), (220), (311), (222), (400), (331) and (420) planes of fluorite cubic crystalline structure of cerium dioxide (JCPDS 34-0394). Since no diffracted peaks of any other byproducts as an impurity is detected, the strong and welldefined peaks firmly indicate the pure cubic structure of cerium dioxide nanoparticles. The mean size of cerium dioxide crystallites was obtained $17.7 \mathrm{~nm}$ using the well-known Debye-Scherrer equation: $(L=K \lambda / \beta \cdot \cos \theta)$ with $\lambda=10, \beta=0.576, K=0.9$, and $2 \theta=28.5$, where $K$ is a shape factor, $\lambda$ is the $\mathrm{X}$-ray wavelength in nanometer, $\beta$ is the full width of the diffraction peak profile at half maximum height in radians, and $\mathrm{K}$ is a constant related to crystallite shape, and $\theta$ is the Bragg 
Angle in radians.

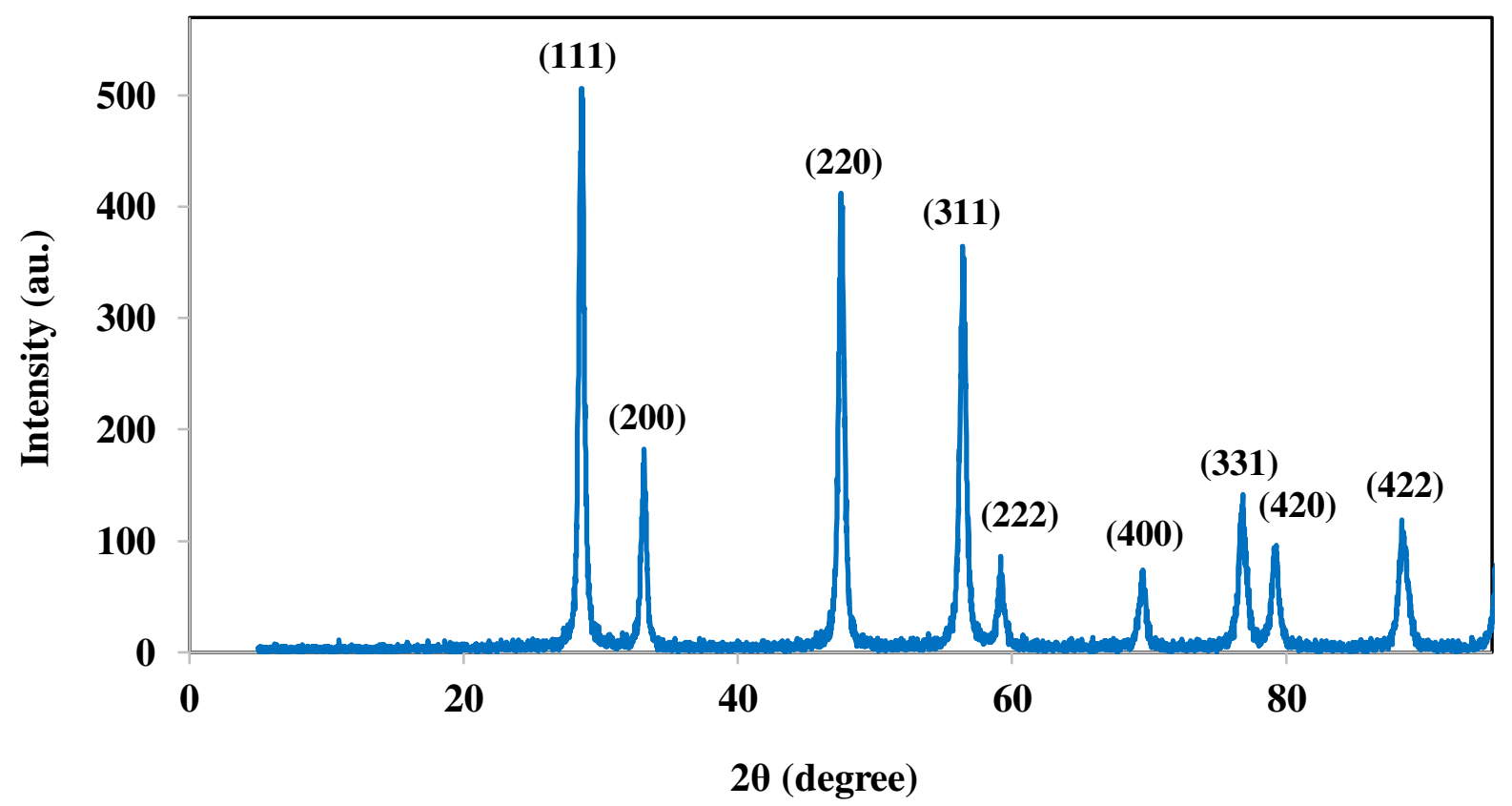

Figure 1. The $\mathrm{X}$-ray diffraction pattern of prepared $\mathrm{CeO}_{2}$ nanoparticles.

According to Figure 2, the scanning electron microscopy of cerium dioxide confirmed the morphology and formation of agglomerated nanoparticles (Figure 2a) using cellulose as a template. The SEM shows that obtained nanoparticles are mostly comprised of 47 to $50 \mathrm{~nm}$ and less of $25 \mathrm{~nm}$ spherical voids (Figure $2 \mathrm{~b}$.). 


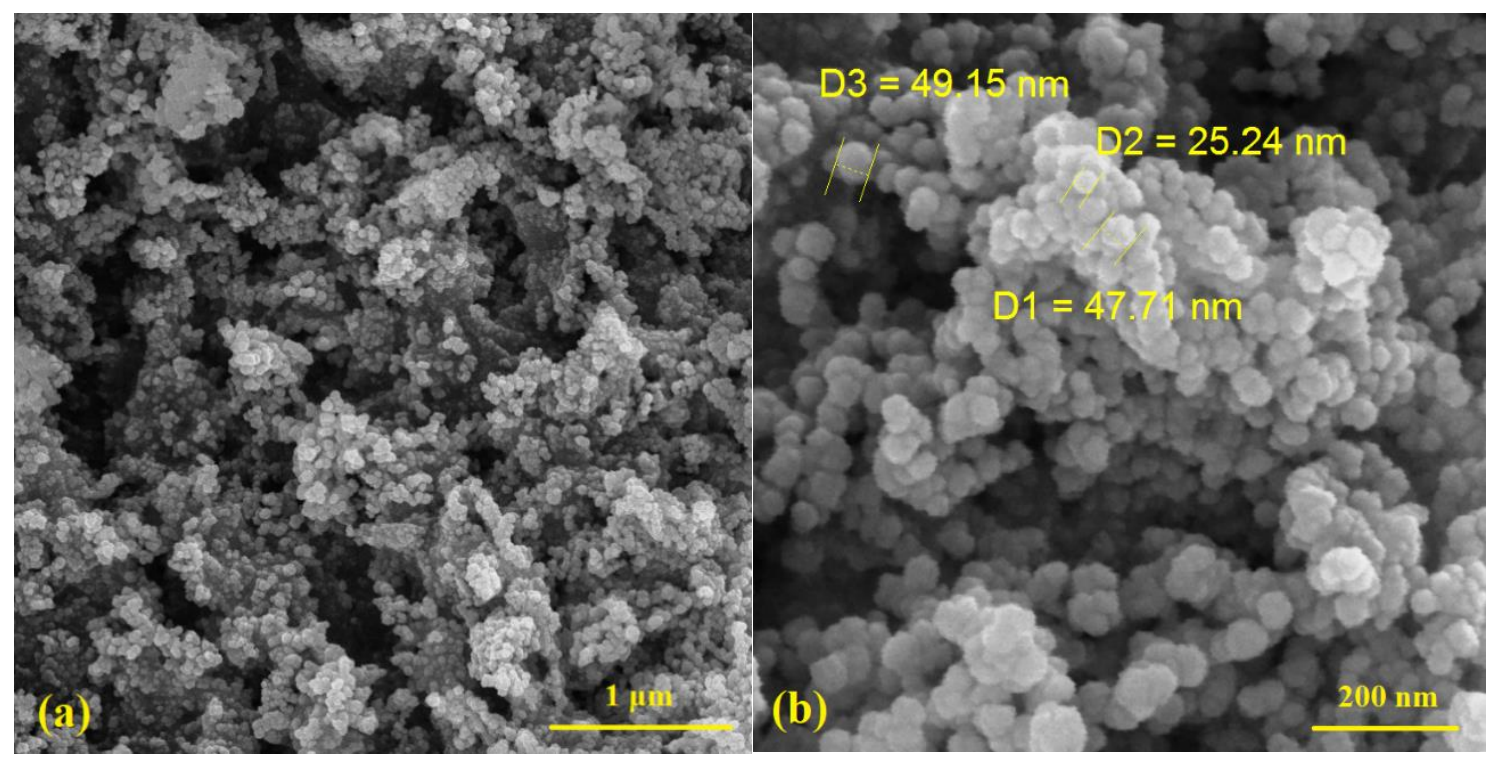

Figure.2. SEM images of the prepared cerium dioxide nanoparticles.

According to the nitrogen adsorption-desorption isotherm plots of the cerium dioxide catalyst using Brunauer-Emmett-Teller (BET) and Barrett-Joyner-Halenda (BJH) methods $815.0864 \mathrm{~m}^{2} \mathrm{~g}^{-}$ ${ }^{1}, 0.191 \mathrm{~cm}^{3} \mathrm{~g}^{-1}$ and $1.7 \mathrm{~nm}$ are corresponded values of specific surface area, pore volume and mean pore diameter values of the prepared catalyst, respectively.

Based on previous studies with slight modification, our preliminary reaction was carried out at $150{ }^{\circ} \mathrm{C}$ for $6 \mathrm{~h}$. (Table 1.) For the first time the reaction of $4.16 \mathrm{mmol} 2$-aminoethanol and 4.16 mmol urea was conducted under solvent free condition with and without cerium dioxide nanoparticles (Entry 1,2). The blank test (Entry 1) with no conversion and no product formation indicated that the presence of cerium dioxide was essential for converting the urea and 2aminoethanol. In our first attempt during $4 \mathrm{~h}$, substrates were converted of about $75 \%$ to a single product identified by gas chromatography as the 2-oxazolidinone. (Entry 2) 
Table 1. Catalytic synthesis of 2-oxazolidinone.

\begin{tabular}{ccccc}
\hline Entry & ${\text { Temperature }\left({ }^{\circ} \mathbf{C}\right)}$ & Time(h) & Conversion (\%) & Selectivity to 2-oxazolidinone (\%) \\
\hline $1^{(\mathrm{a})}$ & 150 & $4 \mathrm{~h}$ & 0 & 0 \\
2 & 150 & $4 \mathrm{~h}$ & $\mathbf{7 5}$ & $\mathbf{1 0 0}$ \\
3 & 150 & $3 \mathrm{~h}$ & 71 & 86 \\
4 & 150 & $6 \mathrm{~h}$ & $\mathbf{8 4}$ & $\mathbf{1 0 0}$ \\
5 & 150 & $8 \mathrm{~h}$ & 89 & 40 \\
6 & 150 & $10 \mathrm{~h}$ & 94 & 1.8 \\
7 & 140 & $6 \mathrm{~h}$ & 72 & 85 \\
8 & 140 & $12 \mathrm{~h}$ & 91 & 87 \\
9 & 170 & $6 \mathrm{~h}$ & 62 & 0 \\
$10^{(\mathrm{b})}$ & 150 & $6 \mathrm{~h}$ & $\mathbf{9 8 . 4}$ & $\mathbf{1 0 0}$ \\
$11^{(\mathrm{c})}$ & 150 & $6 \mathrm{~h}$ & 99 & 11 \\
\hline
\end{tabular}

Reaction conditions: $0.25 \mathrm{ml}$ 2-aminoethanol, $0.25 \mathrm{~g}$ urea, $0.025 \mathrm{~g}$ ceria $(10 \% \mathrm{w}), 150{ }^{\circ} \mathrm{C}$. (a) without catalyst, (b) urea/2aminoethanol: 1.5/1, (c) urea/2-aminoethanol: $2 / 1$

Our further investigations continued with optimizing of the reaction parameters to achieve both high conversion and selectivity to 2-oxazolidione. By performing the reaction for $3 \mathrm{~h}$ conversion and selectivity to 2-oxazolidinone decreased to $71 \%$ and $86 \%$, respectively (Entry 3). In order to complete the reaction and obtain higher conversion, reaction time was increased. After $6 \mathrm{~h}$ conversion raised to $84 \%$ without any loss in selectivity to 2-oxazolidinone (Entry 4) but with further increasing reaction time to $8 \mathrm{~h}$ and $10 \mathrm{~h}$ although the reaction was quite completed and conversion of $89 \%$ and $94 \%$ was obtained but formation of 2-oxazolidinone was disfavored and selectivity decreased significantly to $40 \%$ and $1.8 \%$ (Entry 5, 6). Although the formation of byproducts is not the case to follow in this paper, according to previously proposed possible reactions (Figure 3), with lengthening time, 2-oxaxolidinone can participate in side reactions with residual 2-aminoethanol, urea and produced ammonia which can form 1-(2-hydroxyethyl)-2imidazolidinone (figure 3a.), 2-imidazolidinone (Figure 3b.) and (2-hydroxyethyl) urea (Figure $3 c$.$) respectively [10,26]$. 


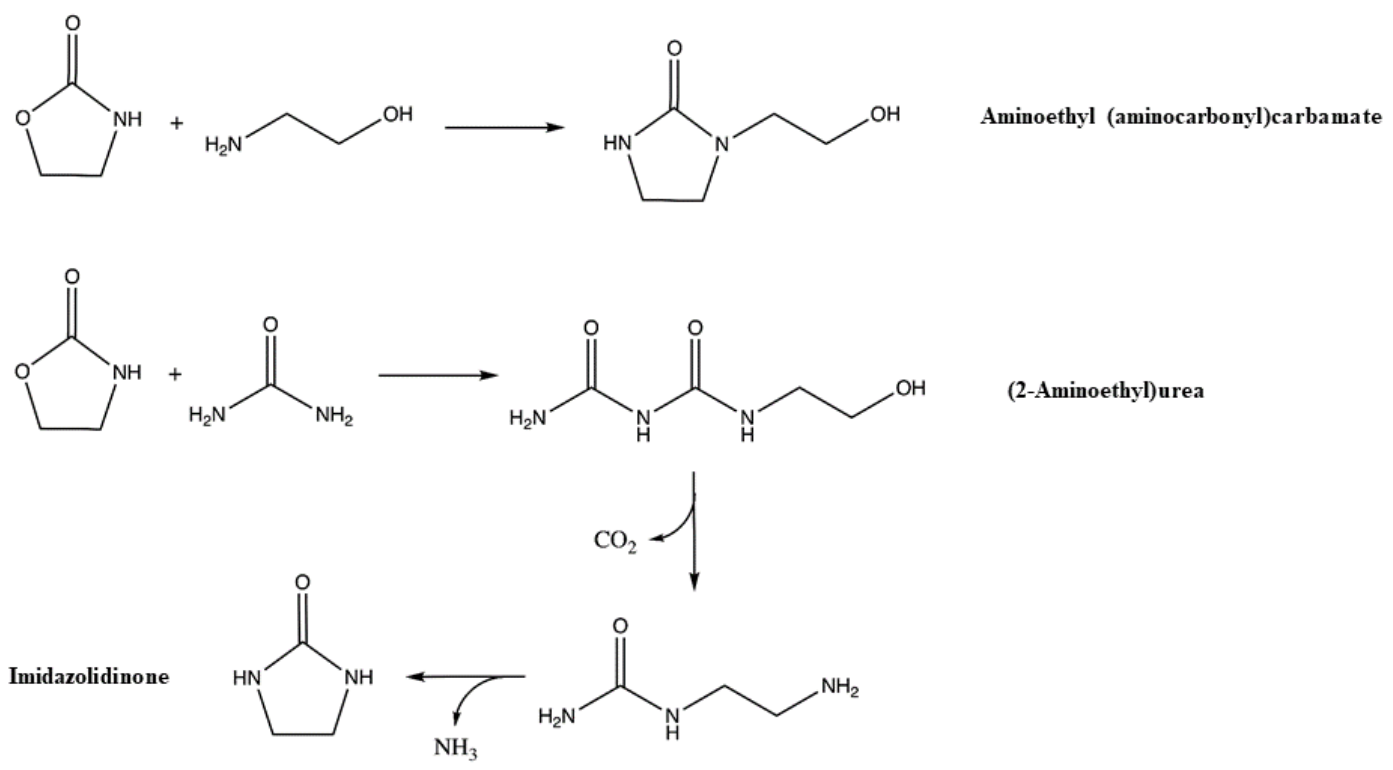

Figure 3. The possible side reactions of 2-oxazolidinone.

To highlight the influence of temperature, the reaction was carried out at a lower temperature of $140{ }^{\circ} \mathrm{C}$, which resulted in a decrease of both conversion and selectivity of 2-oxazolidinone to 72 $\%$ and $85 \%$, respectively (Entry 7). Continuing the reaction for $12 \mathrm{~h}$ at this temperature resulted in a higher conversion of $91 \%$ and a pretty slight increase in selectivity to 2-oxazolidinone of about $87 \%$ (Entry 8 ). Usually, the increase in the reaction temperature results in a quite complete conversion of substrates, but in this case, by increasing the temperature to $170{ }^{\circ} \mathrm{C}$ surprisingly, the conversion dropped to $62 \%$, and 2-oxazolidinone was not formed (Entry 9). The decomposition of urea is temperature-dependent and can either completely decompose to ammonia and carbon dioxide or partially decompose to isocyanic acid and ammonia (Figure 4) [42,43]. The reaction of 2-aminoethanol with both urea and produced carbon dioxide forms 2-oxazolidinone at 140-150 ${ }^{\circ} \mathrm{C}$. An increase in the temperature to $170{ }^{\circ} \mathrm{C}$ leads to complete decomposition and forms carbon dioxide nevertheless, by increasing ammonia, the formation of 2-oxazolidinone thermodynamically is prevented (Figure 4) [26,44]. 


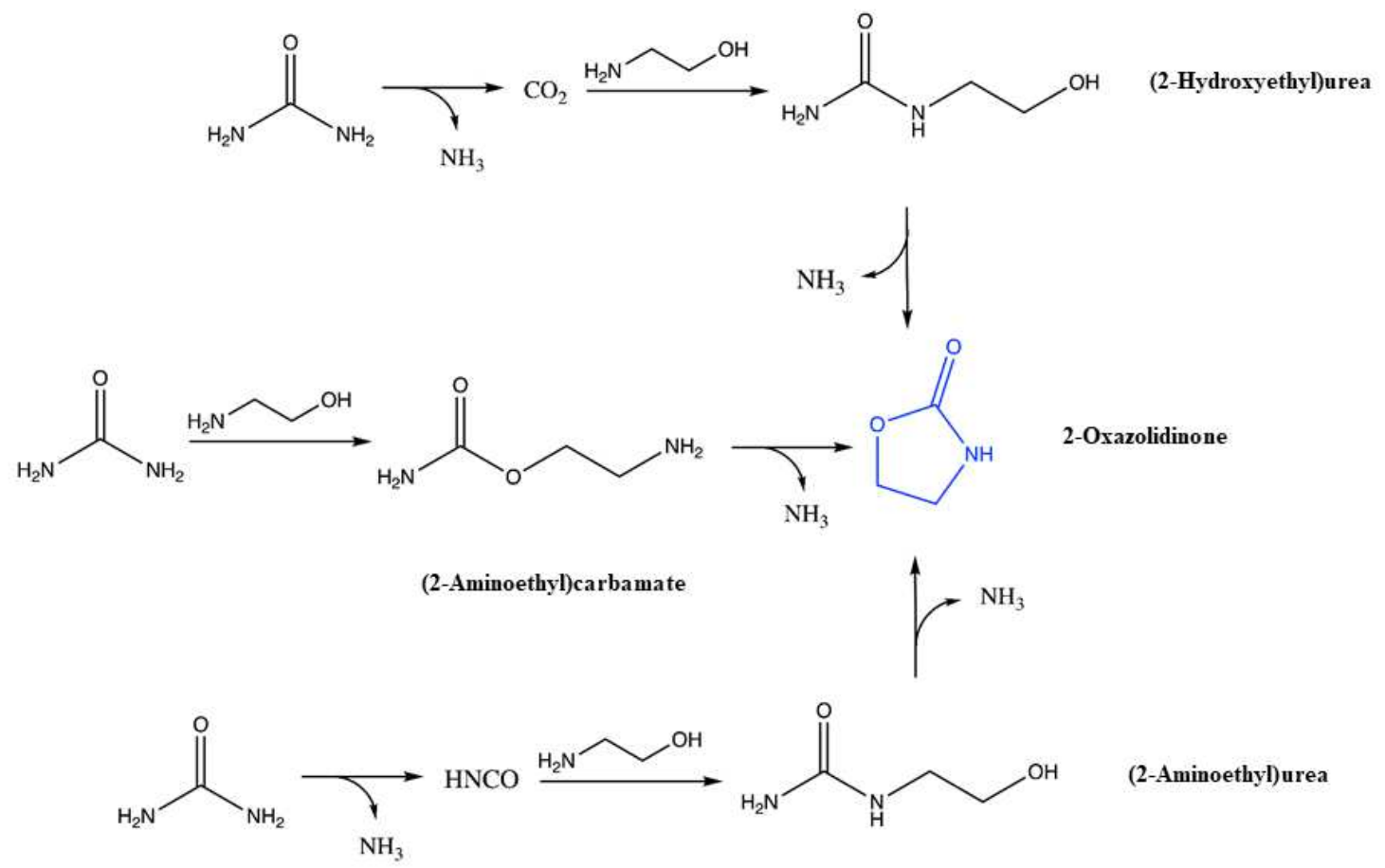

Figure 4. Decomposition of urea at different temperatures.

By changing the substrate scope of urea/2-aminoethanol from 1 to 1.5 ratio, the reaction was nearly completed, and reagents were $98.4 \%$ converted to $100 \%$ 2-oxazolidinone (Entry 10). Furthermore, by adding of more urea and increasing the urea/2-aminoethanol ratio to 2 , the formation of 2-oxazolidinone was disfavored, and selectivity was decreased significantly to $11 \%$ (Entry 11).

Table 2. The influence of the amount of catalyst on the synthesis of 2-oxazolidinone.

\begin{tabular}{cccc}
\hline Entry & Catalyst (w/w \%) & Conversion (\%) & Selectivity to 2-oxazolidinone (\%) \\
\hline 1 & 2.5 & 61 & 0 \\
2 & 5 & 63 & 5.8 \\
3 & 7 & 78 & 66.6 \\
4 & 10 & $\mathbf{9 8 . 4}$ & $\mathbf{1 0 0}$ \\
\hline
\end{tabular}

Reaction conditions: $0.25 \mathrm{ml}$ 2-aminoethanol ,0.5 g urea, $150{ }^{\circ} \mathrm{C}, 6 \mathrm{~h}$. 
At the optimum conditions of the reaction, the amount of the catalyst was varied. Decreasing the catalyst to 7 weight $\%$ resulted in a moderate yield of $66.6 \%$, and with less than $7 \%$, a trace amount of 2-oxazolidinone was produced. The 2-oxazolidinone was the main product of Entry 10, which after the reaction was separated from maintained 2-aminoethanol by column chromatography and was recrystallized, and pure 2-oxazolidinone was analyzed by nuclear magnetic resonance.

${ }^{1} \mathrm{H} \mathrm{NMR}\left(\mathrm{CDCl}_{3}\right): \delta 3.42,4.25,7.4,{ }^{13} \mathrm{C}-\mathrm{NMR}\left(\mathrm{CDCl}_{3}\right): \delta 40.1,60.12,160.1$

Recyclability/reusability of the catalyst was tested using the recyclable cerium dioxide at the optimum reaction conditions, the same as Entry 10. As illustrated in Figure 3, in three consecutive runs, the selectivity to 2-oxazolidinone remained unchanged, and the activity of the synthesized catalyst dropped only $5 \%$, so that the reaction can be repeated in few runs with minimum loss of activity.

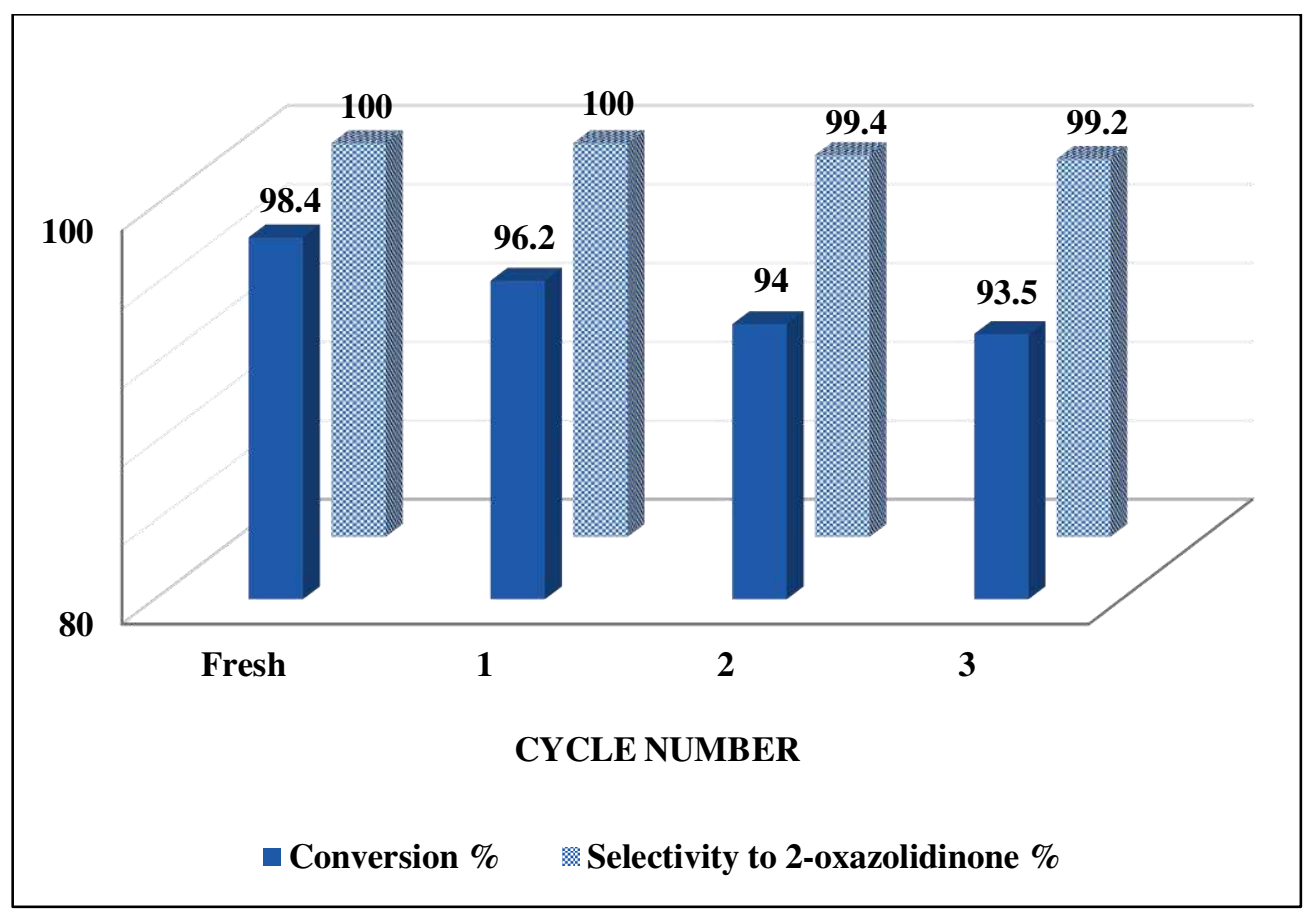

Figure 5. The recyclability of cerium dioxide in four runs.

According to the previously proposed mechanism, which is shown in figure 6 [25], 2-oxazolidinone formation from carbon dioxide and 2-aminoethanol is comprised of four steps: (1) formation of carbonate and carbamate adspecies from absorbed 2-aminoethanol and carbon dioxide on cerium dioxide surface, (2) 
decomposition of carbonate functional group to a hydroxyl group and carbon dioxide, (3) intramolecular nucleophilic addition of hydroxyl group to absorbed carbamate moiety on cerium dioxide providing 2oxazolidinone-coordinated cerium complex, and (4) desorption of produced 2-oxazolidinone and regeneration of cerium dioxide $[10,15]$.

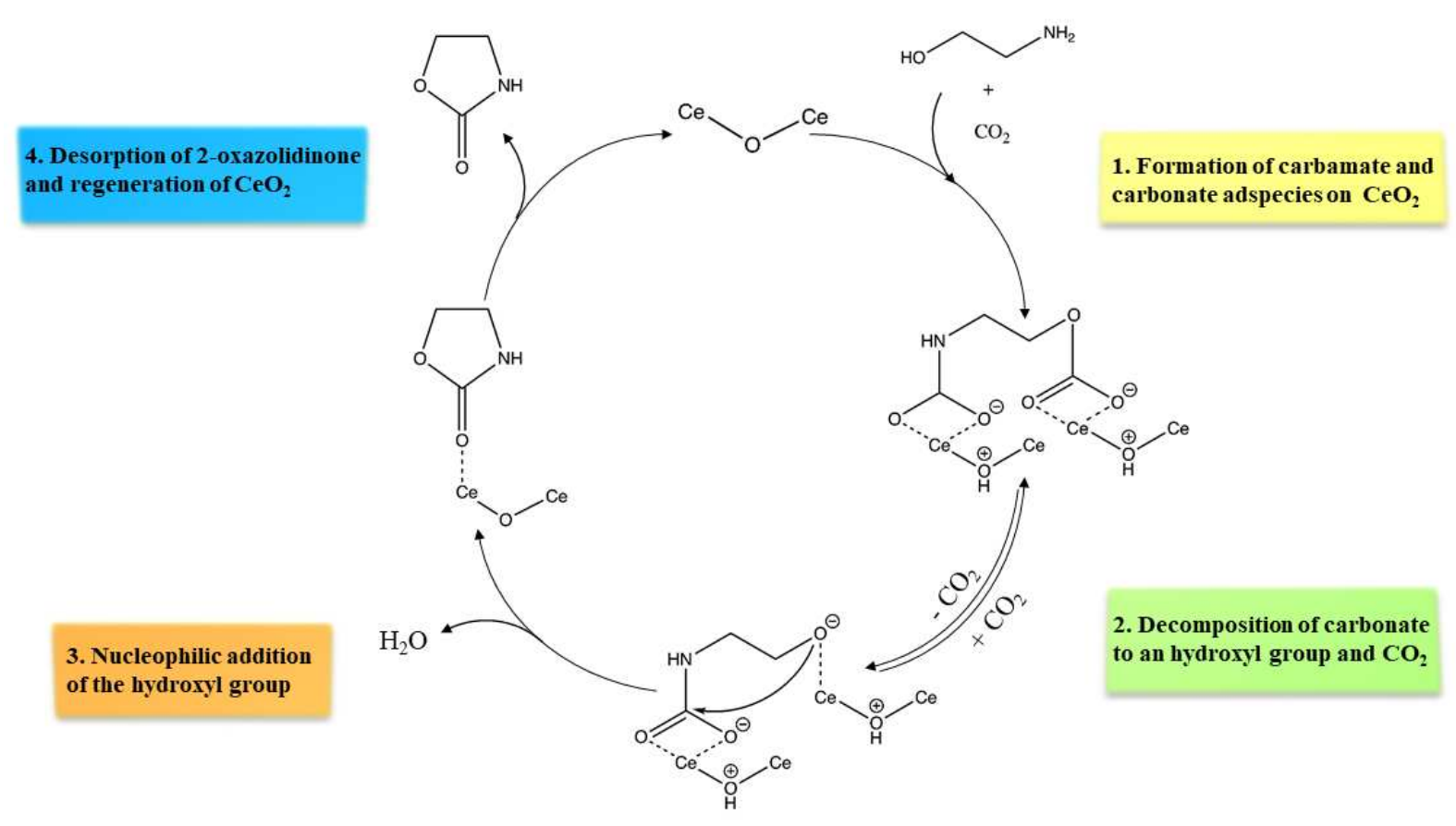

Figure 6. Proposed mechanism for reaction of 2-aminoethanol and $\mathrm{CO}_{2}$ over cerium dioxide.

\section{Conclusion}

In the present study, cerium dioxide nanoparticles were prepared and used for selective solventfree synthesis of 2-oxazolidinone from 2-aminoethanol and urea. Under optimized experimental conditions in this report, $98.4 \%$ conversion of 2 -aminoethanol with $100 \%$ selectivity to 2 oxazolidinone was obtained by cerium dioxide nanoparticles at $150^{\circ} \mathrm{C}$ in 6 hours. The catalyst was used in further reactions checking for recyclability. According to the results, the cerium dioxide was reusable with a negligible loss of activity for at least three runs. 


\section{Acknowledgement}

The authors gratefully acknowledge the financial support from Iran National Science Foundation (INSF).

\section{References}

[1] S.S. Islam, S. Biswas, R. Ali Molla, N. Yasmin, S.M. Islam, ChemNanoMat. (2020) https://doi.org/10.1002/cnma.202000284.

[2] S. Ghosh, T.S. Khan, A. Ghosh, A.H. Chowdhury, M.A. Haider, A. Khan, S.M. Islam, ACS Sustain. Chem. Eng. (2020) https://doi.org/10.1021/acssuschemeng.9b06704.

[3] R.A. Betts, C.D. Jones, J.R. Knight, R.F. Keeling, J.J. Kennedy, El Nin, Nat. Clim. Chang. (2016) http://dx.doi.org/10.1038/nclimate3063.

[4] N.H. Kim, E.Y. Seong, J.H. Kim, S.H. Lee, K.H. Ahn, E.J. Kang, J. CO2 Util. (2019) https://doi.org/10.1016/j.jcou.2019.07.033.

[5] M. Sengoden, M. North, A.C. Whitwood, ChemSusChem. (2019) https://doi.org/10.1002/cssc.201901171.

[6] S. Xia, Y. Song, X. Li, H. Li, L.N. He, Molecules. (2018). https://doi.org/10.3390/molecules23113033.

[7] L. Soldi, C. Massera, M. Costa, N. Della Ca', Tetrahedron Lett. (2014) https://doi.org/10.1016/j.tetlet.2014.01.029.

[8] C. Mei, Y. Zhao, Q. Chen, C. Cao, G. Pang, Y. Shi, ChemCatChem. (2018) https://doi.org/10.1002/cctc.201800142.

[9] A. Bansode, A. Urakawa, ACS Catal. (2014) https://doi.org/10.1021/cs501221q.

[10] M. Tamura, M. Honda, K. Noro, Y. Nakagawa, K. Tomishige, J. Catal. (2013) https://doi.org/10.1016/j.jcat.2013.05.013.

[11] M. Honda, S. Sonehara, H. Yasuda, Y. Nakagawa, K. Tomishige, Green Chem. (2011) https://doi.org/10.1039/c1gc15646b.

[12] R. Yousefi, T.J. Struble, J.L. Payne, M. Vishe, N.D. Schley, J.N. Johnston, J. Am. Chem. Soc. (2019) https://doi.org/10.1021/jacs.8b11793.

[13] T. Niemi, I. Fernández, B. Steadman, J.K. Mannisto, T. Repo, Chem. Commun. (2018) https://doi.org/10.1039/c8cc00636a. 
[14] T. Niemi, T. Repo, European J. Org. Chem. (2019) https://doi.org/10.1002/ejoc.201801598.

[15] X. Zhao, S. Yang, S. Ebrahimiasl, S. Arshadi, A. Hosseinian, J. CO2 Util. (2019) https://doi.org/10.1016/j.jcou.2019.05.004.

[16] U. Atmaca, R. Kaya, H.S. Karaman, M. Çelik, İ. Gülçin, Bioorg. Chem. (2019). https://doi.org/10.1016/j.bioorg.2019.102980.

[17] D. Shinabarger, Expert Opin. Investig. Drugs. (1999) 1195-1202. https://doi.org/10.1517/13543784.8.8.1195.

[18] N. Kudo, M. Taniguchi, S. Furuta, K. Sato, T. Endo, Synthesis and Herbicidal Activities of 4-Substituted 3-Aryl-5- tert -butyl-4-oxazolin-2-ones, (1998)

[19] S.F. Pi, Y.M. Guo, Z.R. Zhou, H.Z. Sun, B. Yi, J. Chem. Res. (2020) https://doi.org/10.1177/1747519820907304.

[20] R. Pal, S. Sudhi, R. Raghavan, J. Appl. Polym. Sci. (2019) https://doi.org/10.1002/app.47520.

[21] T. Nishiyama, Y. Iwasaki, F. Yamada, J. Heterocycl. Chem. (1986) https://doi.org/10.1002/jhet.5570230114.

[22] J.M. Liu, X.G. Peng, J.H. Liu, S.Z. Zheng, W. Sun, C.G. Xia, Tetrahedron Lett. (2007) https://doi.org/10.1016/j.tetlet.2006.12.028.

[23] X. Wu, J. Mason, M. North, Chem. - A Eur. J. (2017) https://doi.org/10.1002/chem.201702948.

[24] Y. Toda, S. Gomyou, S. Tanaka, Y. Komiyama, A. Kikuchi, H. Suga, Org. Lett. (2017) https://doi.org/10.1021/acs.orglett.7b02722.

[25] S. Farshbaf, L.Z. Fekri, M. Nikpassand, R. Mohammadi, E. Vessally, J. CO2 Util. (2018) https://doi.org/10.1016/j.jcou.2018.03.020.

[26] A. Dibenedetto, F. Nocito, A. Angelini, I. Papai, M. Aresta, R. Mancuso, ChemSusChem. (2013) https://doi.org/10.1002/cssc.201200524.

[27] M. Peña-López, H. Neumann, M. Beller, Angew. Chemie - Int. Ed. (2016) https://doi.org/10.1002/anie.201600698.

[28] F. Shi, Y. Deng, T. SiMa, J. Peng, Y. Gu, B. Qiao, Angew. Chemie - Int. Ed. (2003) https://doi.org/10.1002/anie.200351098.

[29] P. Wang, Q. Li, S. Liu, Y. Deng, RSC Adv. (2016) https://doi.org/10.1039/c6ra21809a. 
[30] C.J. Dinsmore, S.P. Mercer, Org. Lett. (2004) https://doi.org/10.1021/o10491080.

[31] M. Kodaka, T. Tomohiro, H. Okuno, J. Chem. Soc. Chem. Commun. (1993) https://doi.org/10.1039/C39930000081.

[32] J. Paz, C. Pérez-Balado, B. Iglesias, L. Muñoz 2-oxazinones, and cyclic ureas: Scope and limitations, J. Org. Chem. (2010) https://doi.org/10.1021/jo100268n.

[33] S. Pulla, C.M. Felton, Y. Gartia, P. Ramidi, A. Ghosh, ACS Sustain. Chem. Eng. (2013) https://doi.org/10.1021/sc300077m.

[34] J.P. Nicot, I.J. Duncan, Greenh. Gases Sci. Technol. (2012) https://doi.org/10.1002/ghg.

[35] S.I. Fujita, H. Kanamaru, H. Senboku, M. Arai, Int. J. Mol. Sci. (2006) https://doi.org/10.3390/i7100438.

[36] T. Baronsky, C. Beattie, R.W. Harrington, R. Irfan, M. North, J.G. Osende, C. Young, ACS Catal. (2013) https://doi.org/10.1021/cs4001046.

[37] C. Beattie, M. North, RSC Adv. (2014) https://doi.org/10.1039/c4ra04427d.

[38] S.K. Alamsetti, A.K.. Persson, J.E. Bäckvall, Org. Lett. (2014) https://doi.org/10.1021/o15002279.

[39] P. Wang, J. Qin, D. Yuan, Y. Wang, Y. Yao, ChemCatChem. (2015) https://doi.org/10.1002/cctc.201403015.

[40] M. Tamura, M. Honda, Y. Nakagawa, K. Tomishige, J. Chem. Technol. Biotechnol. (2014) https://doi.org/10.1002/jctb.4209.

[41] R. Juárez, P. Concepción, A. Corma, H. García, Chem. Commun. (2010) https://doi.org/10.1039/c001955k.

[42] S.D. Yim, S.J. Kim, J.H. Baik, I.S. Nam, Y.S. Mok, J.H. Lee, B.K. Cho, S.H. Oh, Ind. Eng. Chem. Res. (2004) https://doi.org/10.1021/ie034052j.

[43] B. Lv, B. Guo, Z. Zhou, G. Jing, Environ. Sci. Technol. (2015) https://doi.org/10.1021/acs.est.5b02356.

[44] E.F. Da Silva, H. Lepaumier, A. Grimstvedt, S.J. Vevelstad, A. Einbu, K. Vernstad, H.F. Svendsen, K. Zahlsen, Ind. Eng. Chem. Res. (2012) https://doi.org/10.1021/ie300718a. 


\section{Graphical abstract:}

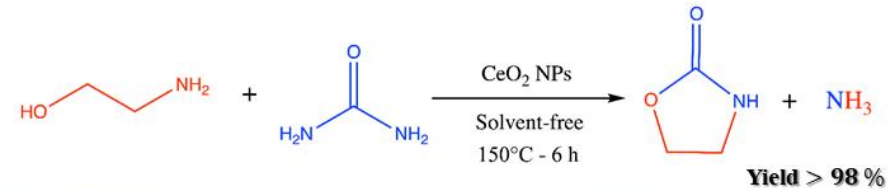

$$
\begin{array}{ll}
\text { Indirect carbon dioxide fixation } & >\text { High yield } \\
\text { Easy preparation and reusability of the catalyst } & >\text { Solvent-free condition } \\
\text { Excellent selectivity to 2-oxazolidinone } & >\text { Low cost reagents }
\end{array}
$$




\section{Figures}

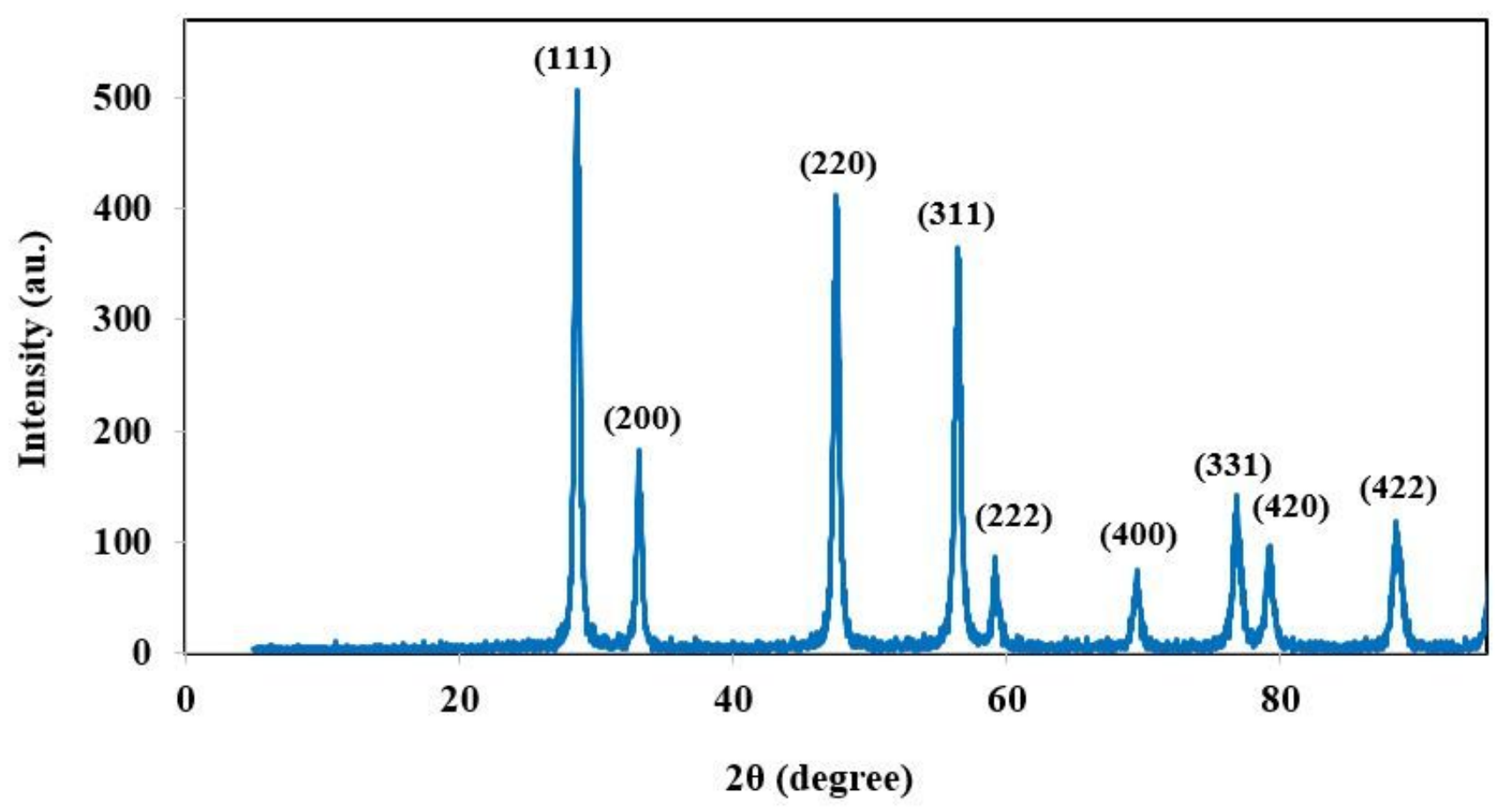

Figure 1

The X-ray diffraction pattern of prepared $\mathrm{CeO} 2$ nanoparticles.

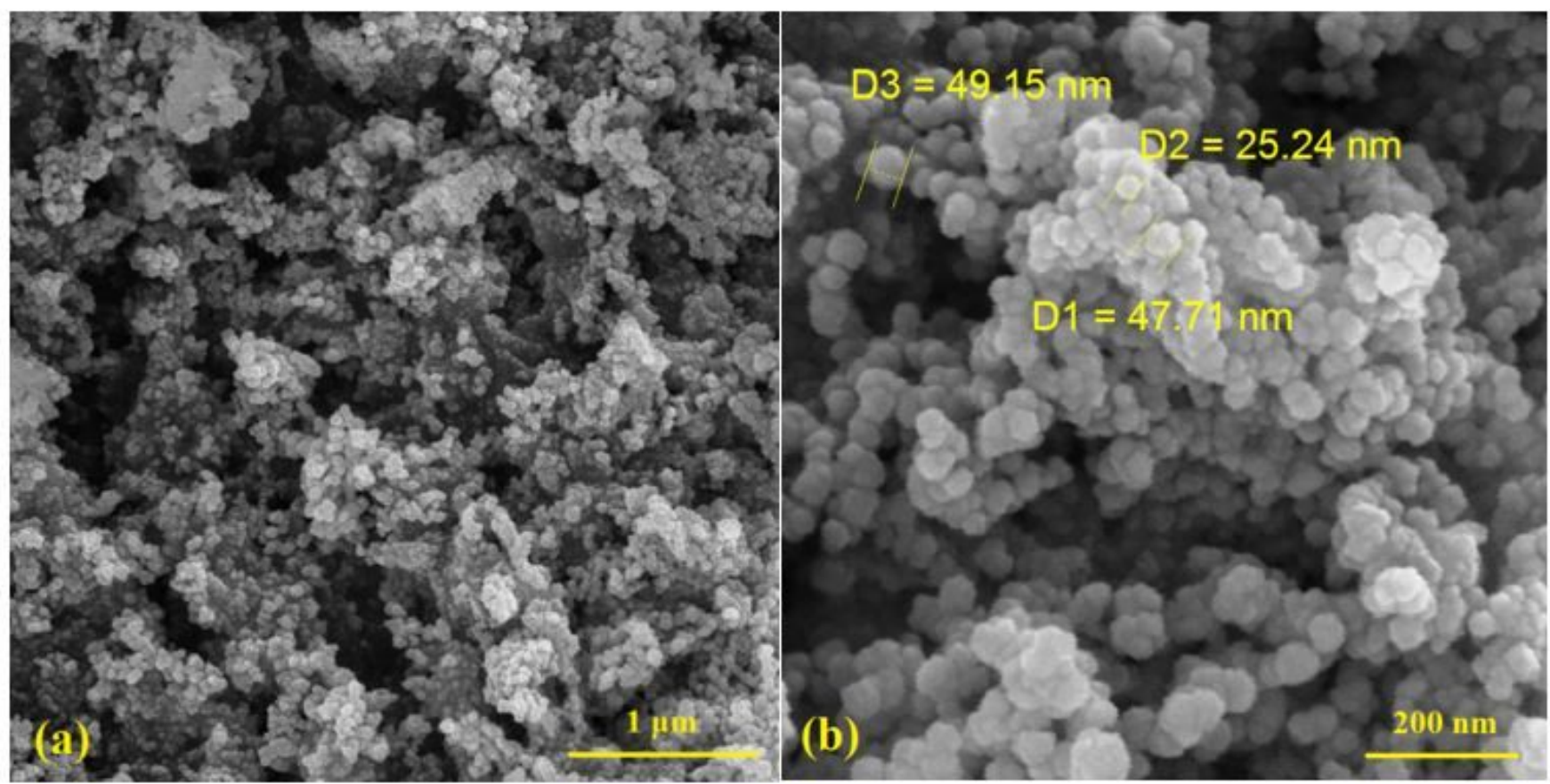

Figure 2 
SEM images of the prepared cerium dioxide nanoparticles.

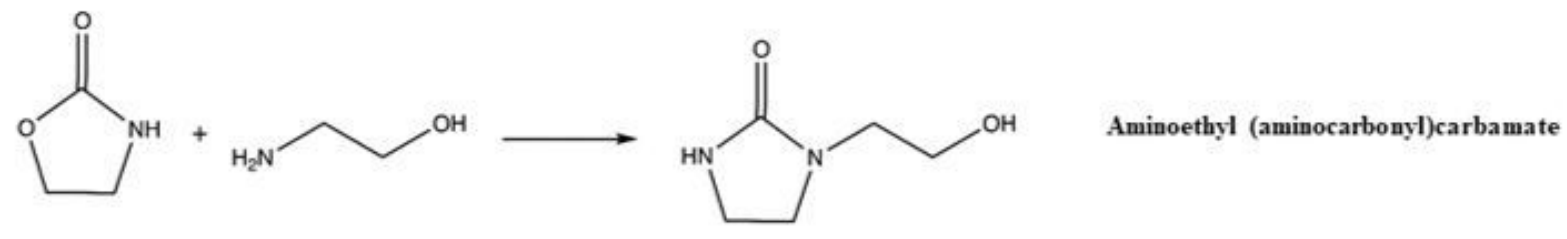<smiles>NC(=O)NC(=O)NCCO</smiles>

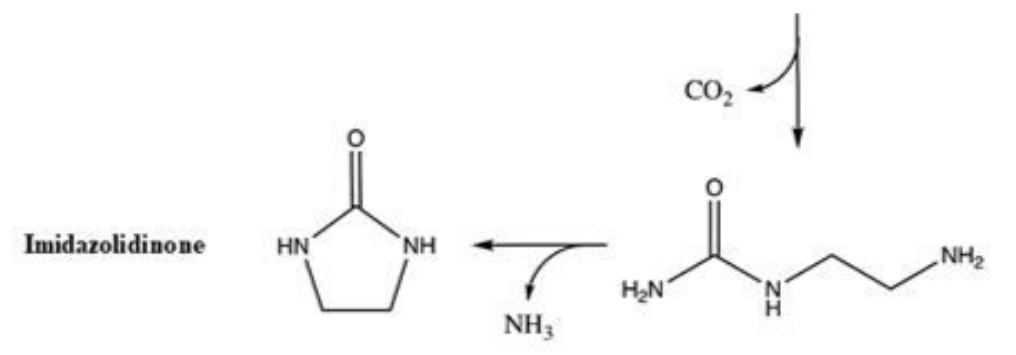

\section{Figure 3}

The possible side reactions of 2-oxazolidinone.

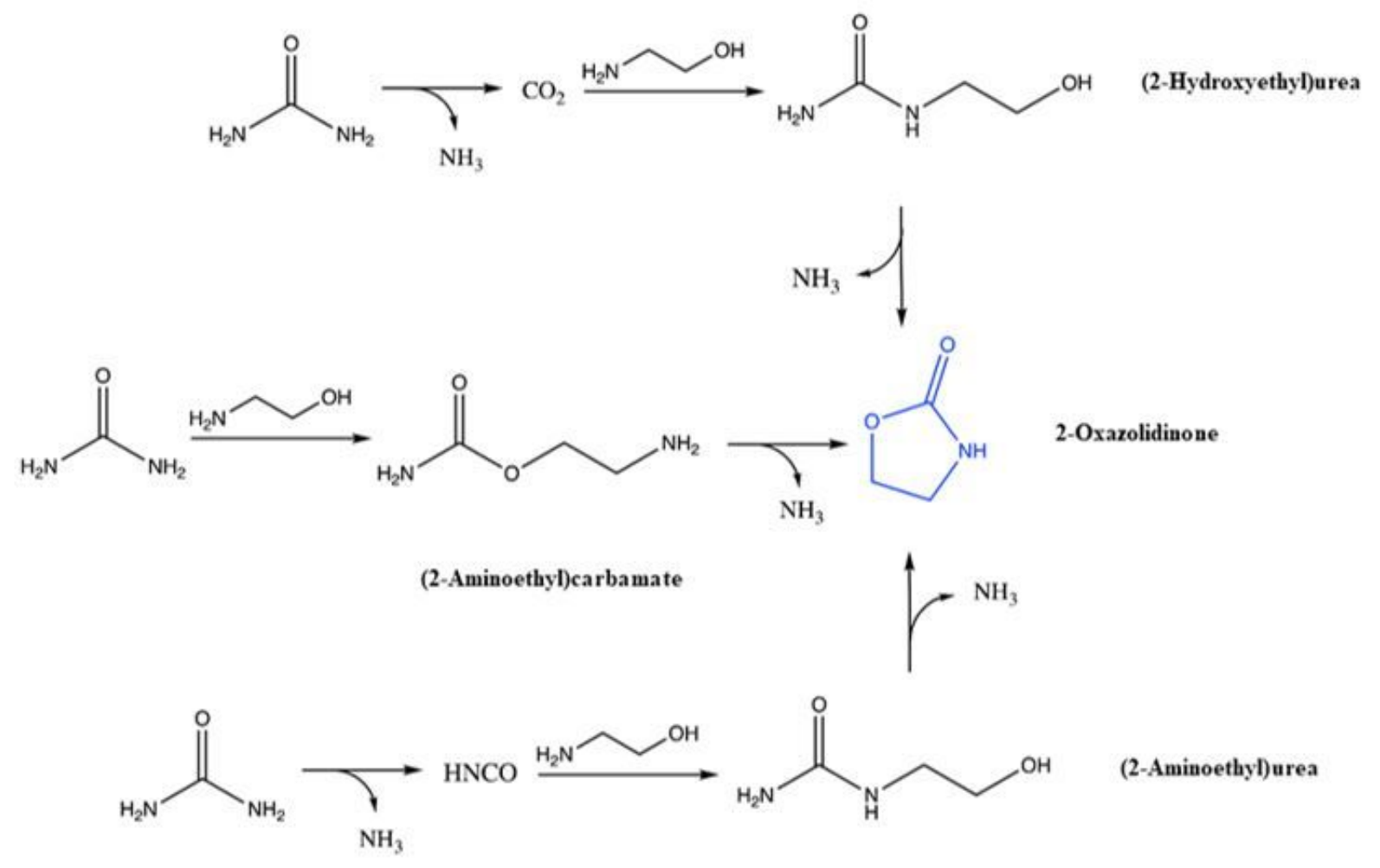


Figure 4

Decomposition of urea at different temperatures.

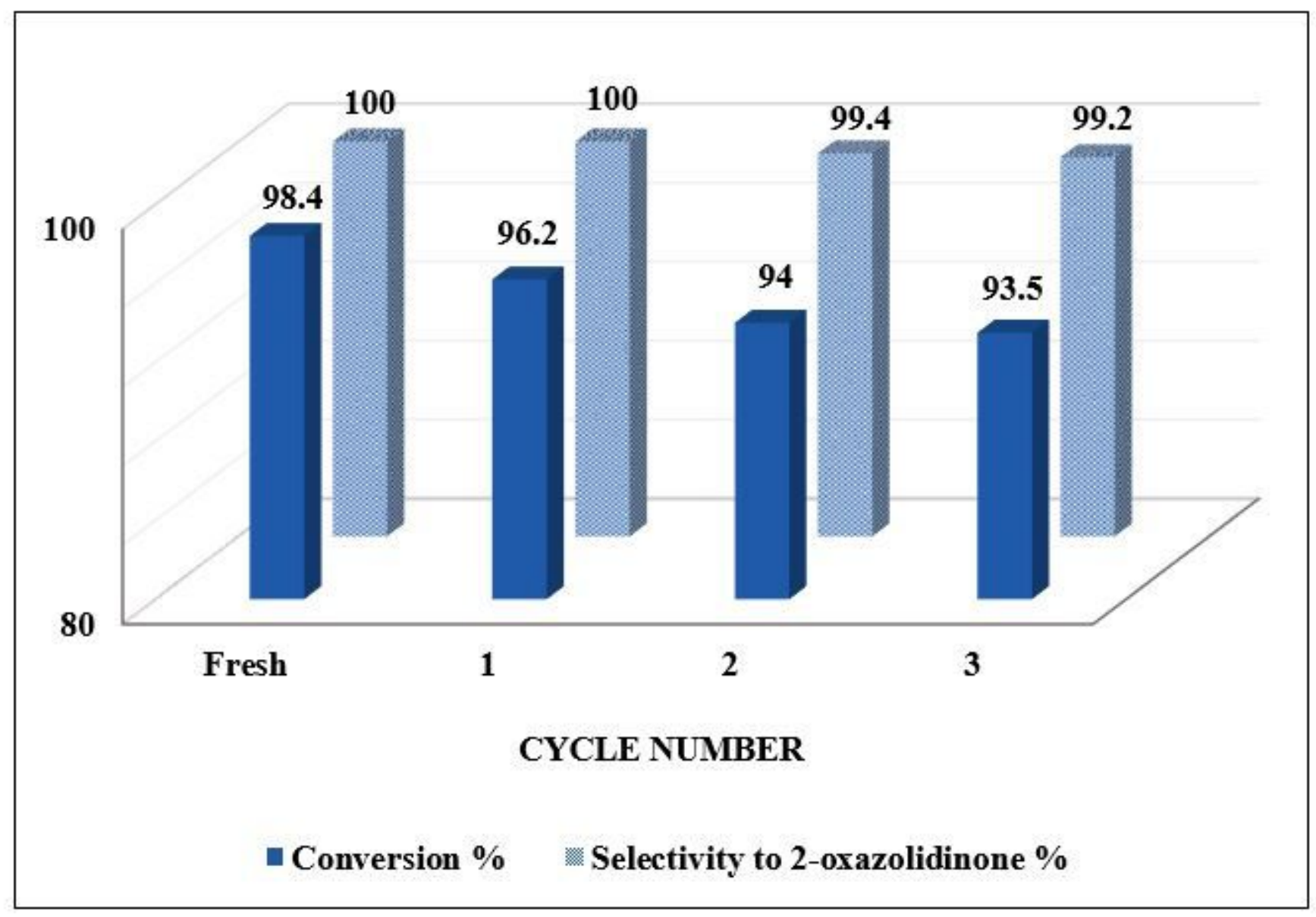

Figure 5

The recyclability of cerium dioxide in four runs. 


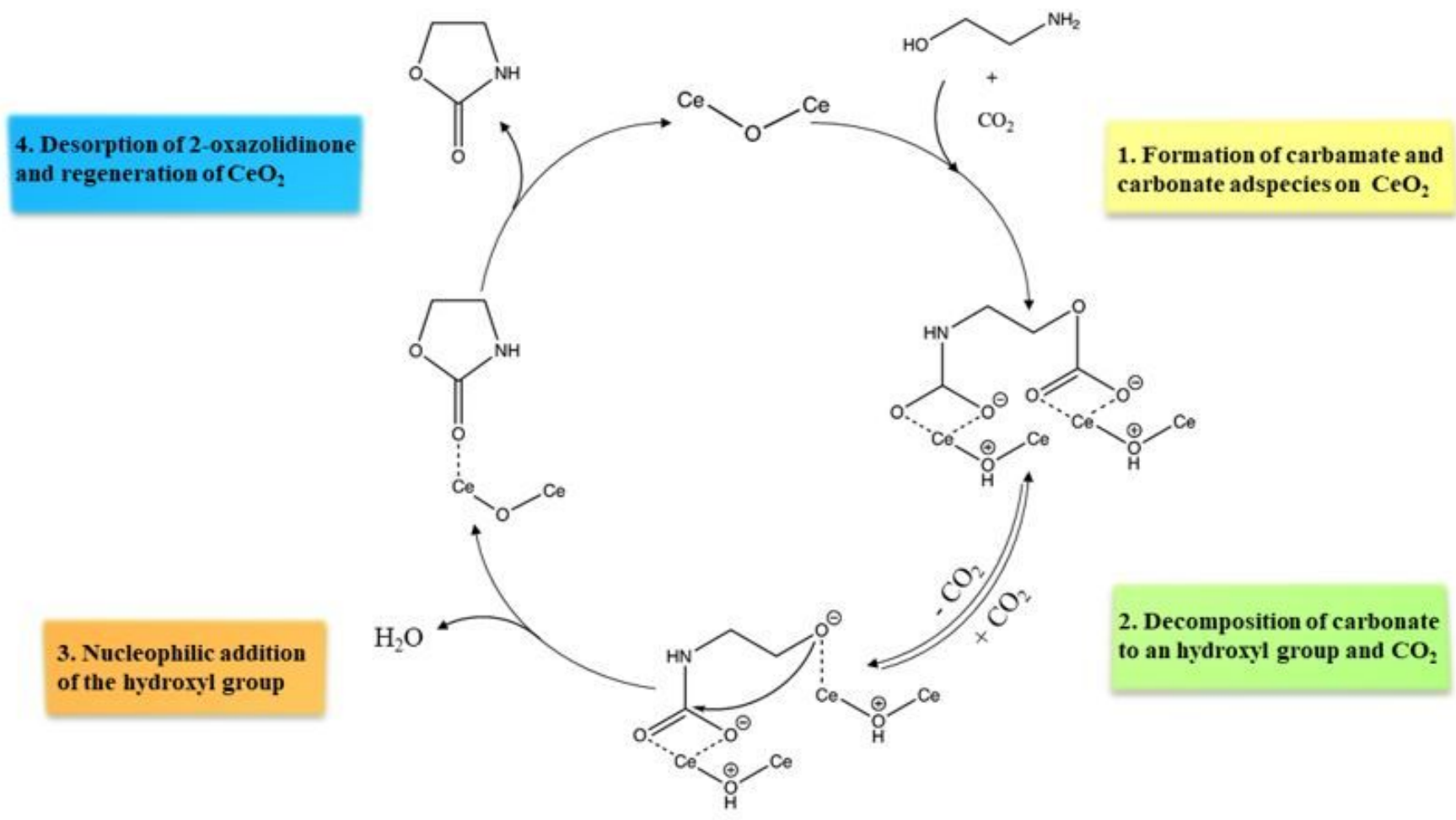

Figure 6

Proposed mechanism for reaction of 2-aminoethanol and $\mathrm{CO} 2$ over cerium dioxide.

\section{Supplementary Files}

This is a list of supplementary files associated with this preprint. Click to download.

- ga.jpg 